\title{
Preparation of recombinant human bone morphogenetic protein-2 loaded dextran-based microspheres and their characteristics ${ }^{1}$
}

\author{
Fa-ming $\mathrm{CHEN}^{2,3}$, Zhi-fen $\mathrm{WU}^{3}$, Qin-tao $\mathrm{WANG}^{3}$, Hong $\mathrm{WU}^{4}$, Yong-jie ZHANG ${ }^{2}$, Xin NIE ${ }^{2}$, Yan JIN ${ }^{2,5}$ \\ ${ }^{2}$ Center for Tissue Engineering, College of Stomatology; ${ }^{3}$ Department of Periodontology and Mucosal Diseases, College of Stomatology; \\ ${ }^{4}$ Department of Chemistry, Faculty of Preclinical Medicine, the Fourth Military Medical University, Xi-an 710032, China
}

\section{Key words}

bone morphogenetic proteins; drug delivery system; sustained-release; tissue regeneration

\footnotetext{
${ }^{1}$ Project supported by Hi-Tech Research and Development Program (863 Program) of China (No 2002AA205041).

${ }^{5}$ Correspondence to Prof Yan JIN.

Phn 86-29-8337-6147.

Fax 86-29-8321-8039.

E-mail yanjin@fmmu.edu.cn
}

Received 2005-04-06

Accepted 2005-05-23

doi: $10.1111 / \mathrm{j} .1745-7254.2005 .00180 . \mathrm{x}$

\begin{abstract}
Aim: To prepare new pharmaceutical forms with sustained delivery properties of recombinant human bone morphogenetic protein-2 $\left(\mathrm{rhBMP}_{2}\right)$ for tissue engineering and guided tissue regeneration (GTR) use. Methods: rhBMP ${ }_{2}$-loaded dextranbased hydrogel microspheres ( $\left.\mathrm{rhBMP}_{2}-\mathrm{MPs}\right)$, which aimed to keep rhBMP ${ }_{2}$ bioactivity and to achieve long-term sustained release of $\mathrm{rhBMP}_{2}$, were prepared by double-phase emulsified condensation polymerization. The physical, chemical performances and biological characteristics of those microspheres were studied both in vitro and in vivo. Results: The microspheres' average diameter was $30.33 \pm 4.32 \mu \mathrm{m}$ with $75.4 \%$ ranging from $20 \mu \mathrm{m}$ to $40 \mu \mathrm{m}$ and the drug loading and encapsulation efficiency were $7.82 \%$ and $82.25 \%$, respectively. The $\mathrm{rhBMP}_{2}-$ releasing profiles in vitro showed that $\mathrm{rhBMP}_{2}$ release could be maintained more than $10 \mathrm{~d}$. The $\mathrm{rhBMP}_{2}-\mathrm{MPs}$, with good swelling and biodegradation behavior, could be kept for 6 months at below $4{ }^{\circ} \mathrm{C}$ without significant characteristic change or bioactivity loss. Cytology studies showed that $\mathrm{rhBMP}_{2}$-MPs could promote the proliferation of periodontal ligament cells (PDLCs) approximately $10 \mathrm{~d}$, while the bioactivity of concentrated $\mathrm{rhBMP}_{2}$ solution could keep no more than $3 \mathrm{~d}$. Scanning electron microscope showed that $\mathrm{rhBMP}_{2}$-MPs could be enchased into the porous structure of calcium phosphate ceremic (CPC) and the eugonic growth of PDLCs in $\mathrm{CPC} / \mathrm{rhBMP}_{2}$-MPs scaffolds. Animal experiments indicated that using $\mathrm{CPC} / \mathrm{rhBMP}_{2}-\mathrm{MPs}$ scaffolds could gain more periodontal tissue regeneration than using rhBMP 2 compound firsthand with $\mathrm{CPC}\left(\mathrm{CPC} / \mathrm{rhBMP}_{2}\right)$. Conclusion: By encapsulating rhBMP ${ }_{2}$ into dextran-based microspheres, a small quantity of rhBMP $_{2}$ could achieve equivalent effects to the concentrated $\mathrm{rhBMP}_{2}$ solution and at the same time, could prolong $\mathrm{rhBMP}_{2}$ retention both in vitro and in vivo.
\end{abstract}

\section{Introduction}

Tissue engineering is one of the biomedical technologies used to induce tissue regeneration or repair body defects. The goal is to isolate adult stem cells in the tissue, then grow them in experimental devices into types of tissue that can be placed into injured regions to promote regeneration of tissue in and around injured areas of the body ${ }^{[1,2]}$. Drug delivery is an area in which chemical engineers have had a major impact, particularly for controlled delivery of pharmaceuticals to specific target sites such as tumors. Gene therapy is really metabolic engineering combined with drug delivery. It is a quantitative problem requiring a systems analysis. The right genes need to be delivered to the desired tissues, and proteins from that gene need to be made at the right time in the right amount. The lack of success with gene therapy is, at least in part, due to the inability of medical scientists to deal with these issues of well-controlled gene delivery and gene expression. This is a broad area that includes materials that are produced using biological processes 
and biologically compatible materials that are used for drug delivery and other medical applications. However, questions pertaining to the scarce resources and the potential risk of seed cells, the biomaterials of scaffold and the methods used to design the cell and scaffold complex remain unresolved, which have resulted in their limited clinical application $^{[3-5]}$. So far, several research approaches - both in animal experiments and in clinical treatment - have been attempted to promote tissue regeneration by bioactive agents, including members of the bone morphogenic protein, transforming growth factor, and insulin-like growth factor families, which are important to the maintenance and repair of most tissue defects ${ }^{[6-8]}$. Since periodontal tissue defects typically remain unhealed and often lead to further tissue degeneration and the loss of teeth, understanding the physiological role of these proteins in the wound-healing cascade and tissue regeneration is of critical importance in advancing the treatment of periodontal tissue loss and in enhancing periodontal tissue regeneration. Most of the research in this field has centered on examining the therapeutic effects that these molecules have on hard or soft tissues with the presence of 1 or more growth factors ${ }^{[9-16]}$. However, as the fields of tissue engineering and biomaterials merge with molecular and cellular biology, new drug delivery vehicles can be utilized to study the in vivo effect of these molecules on periodontal tissue regeneration or periodontal defect repair. Accordingly, this paper details the design and development of a genus of new composite scaffolds with the sustained delivery property of recombinant human bone morphogenetic protein-2 $\left(\mathrm{rhBMP}_{2}\right)$.

Bone morphogenetic proteins (BMPs) have been shown to modulate the wound-healing response in both hard and soft tissues. During the past decade, many investigators have demonstrated the anabolic effects of these wound-healing molecules on the promotion of periodontal attachment structures, namely alveolar bone, periodontal ligament and tooth root cementum ${ }^{[6-8,10-13]}$. However, because of their drawbacks such as short-term BMP retention and losable BMP biological activity in vivo, using agents for BMPs sustained release is of great importance. Although many agents such as calcium phosphate cement (CPC), collagen, bioactive glass ceramic (BGC), hydroxyapaite (HA) and more recently, some hydrogels have been used to enhance tissue regeneration and have gained good results. The actual effect is still uncertain considering the time BMP bioactivity might keep in vivo, as those materials themselves could not preserve BMPs from humoral dilution, metabolized and degraded action. There is evidence that the continuous presence of some growth factors at the periodontal tissue interface to provide a tangible effect is essential, which can accelerate the soft and hard tissue regeneration ${ }^{[6-8,17]}$. Therefore, it is rather inviting to search for new pharmaceutical forms that can sustain elevated growth factor levels and increase or improve tissue regeneration in periodontal diseases treatment or periodontal defect repair ${ }^{[18-20]}$.

Microspheres as drug carriers have the advantage of sustained or controlled release, passive or active drug targeting to specific tissues, which notably reduce the side effects of drugs and improve their bioavailability. Therefore, microspheres as a drug delivery system have drawn much attention in the pharmaceutical field and have been successfully used in tumor chemotherapeutics and in the treatment of diabetes. Dextran-based hydrogels are widely used polymers in pharmaceutical products. The good biocompatibility, the degradation to non-toxic and readily excreted products were the main attractive characteristics of dextran-based hydrogels, which suggest its use in the drug delivery field ${ }^{[21]}$. In addition, dextran is relatively cheap and dextran-co-gelatin hydrogels have putative bioadhesive properties that allow the drug delivery systems, designed in different forms, to meet the need of periodontal tissues and mucosal tissues, as well as other especial tissues, such as the eye, nasal, gastrointestinal and urinary epithelial tissues ${ }^{[22-24]}$. In order to improve the therapeutic efficiency and to prolong BMP retention in periodontal bone defects, and to explore the possibility of preparing targeted $\mathrm{rhMP}_{2}$ delivery devices, this study was aimed at developing a new kind of $\mathrm{rhBMP}_{2}$ delivery system: $\mathrm{rhBMP}_{2}$-loaded dextran-based microspheres (rhBMP $\left.{ }_{2}-\mathrm{MPs}\right)$. The results indicated that using this delivery system could result in a long-term release of $\mathrm{rhBMP}_{2}$ and could enhance periodontal tissue regeneration continually when compounded with tissue engineering scaffold materials.

\section{Materials and methods}

Materials Dextran ( $M_{\mathrm{r}} 69800$ with 5\% branches) was purchased from Xia-si Biomaterial Inc (Beijing, China), Gelatin G-6650 was obtained from Sigma (Sigma Chemicals, SaintLouis, MO, USA) and dried at $60^{\circ} \mathrm{C}$ in a vacuum oven for $2 \mathrm{~d}$. Span-80 and Dextranase (400-800 U/mg protein) was also purchased from Sigma. Triethylamine, 2,20-dimethoxy-2phenyl acetophenone (DMAP), dimethyl formamide (DMF), $N$-methyl pyrrolidone (NMP) and $N, N, N^{\prime}, N^{\prime}$ - tetramethylethylene diamine (TEMED) were obtained from E Merk (Mumbai, India). Glycidyl methacrylate (GMA) was purchased from Bioengineering Inc (Boston, MA, USA). All these materials were dried overnight at $70{ }^{\circ} \mathrm{C}$ in a vacuum oven. $\mathrm{RhBMP}_{2}$ were obtained from the Academy of Military 
Medical Science (Beijing, China), acrylic acid (AA, Merck) was used after vacuum distillation. Water was double distilled. All other chemicals and solvents were used without further purification.

Preparation of $\mathbf{r h B M P} \mathbf{P}_{2}$-MPs Using dextran and GMA, we synthesized the dex-GMA precursor as the method we reported recently with some modifications ${ }^{[25]}$. The synthesized procedure was as follows: Dextran was dissolved in a dimethyl sulphoxide( $\left.\mathrm{Me}_{2} \mathrm{SO}\right)$ solvent system $(60 \mathrm{~mL}$ with Span-80 0.4 mL and TEMED 0.2 mL, DMAP 1.5 g, DMF $0.2 \mathrm{~g}$ and NMP $0.2 \mathrm{~g}$ ) at $60^{\circ} \mathrm{C}$ under $\mathrm{N}_{2}$ gas and stirred for $15 \mathrm{~min}$. After dissolving, the solution was cooled down to $35^{\circ} \mathrm{C}$ and GMA was then slowly added to the dextran solution. The reaction was conducted at $35^{\circ} \mathrm{C}$ for $72 \mathrm{~h}$ under $\mathrm{N}_{2}$ gas. The reaction product was precipitated with cold isopropyl alcohol, filtered, washed several times with isopropyl alcohol, and then freeze-dried in a vacuum oven. The degree of substitution (DS) of the dex-GMA precursor was estimated by the ${ }^{1} \mathrm{H}-\mathrm{NMR}$ method. There is an anomeric proton attached to the $\mathrm{C} 1$ position of the dextran glucose ring that appears at 4.5-5.5 ppm in the NMR spectrum, where the protons of the hydroxyl groups appear. This proton does not react during the GMA substitution reaction, while some of the other protons of other hydroxyl groups are substituted by GMA. So, we can use the ratio of the normalized, integrated intensities of the sum of the hydroxyl group peaks to the normalized, integrated intensities of the anomeric proton peak to estimate the DS. For unsubstituted pure dextran, the ratio should be 3; while for GMA-substituted dextran, this ratio should be less than 3, and the magnitude would depend on the number of substitution. Thus, the DS could be calculated from the ratio: $3 \times$ (difference of the NMR proton intensity between dextran and dextran derivatives)/dextran. The dex-GMA precursor synthesized in this study had a DS of 2.6, that is, 2.6 hydroxyl groups per dextran glucose ring were substituted by GMA. Using dex-GMA, we synthesized a species of biodegradable poly (dex-GMA-co-gelatin) hydrogel microspheres, which were used as the carrier of $\operatorname{rhBMP}_{2}$. The rhBMP 2 -MPs were prepared by double-phase emulsified condensation polymerization method and optimal preparation parameters were obtained by the orthogonal design. The technique was as follows: 3 cuvettes of equivalent homogeneous aqueous dex-GMA and gelatin solution (10\%, $\mathrm{w} / \mathrm{v}$ ) of $6 \mathrm{~mL}$, each containing $0.6 \mathrm{~g}$ dex-GMA and $0.15 \mathrm{~g}$ gelatin, were preheated to $30^{\circ} \mathrm{C}$ and dropped into 3 different reactor systems comprising of $30 \mathrm{~mL}$ paraffin liquid, $0.2 \mathrm{~mL}$ Span- 80 and $0.01 \mathrm{~mL}, 0.02 \mathrm{~mL}$, or $0.03 \mathrm{~mL}$ TEMED. The 3 reactor systems were at $30{ }^{\circ} \mathrm{C}$ in a water bath, forming a water-in-oil emulsion by stirring with a two-paddle stirrer.
Ten minutes later, as the emulsion was obtained, concentrated $\mathrm{rhBMP}_{2}$ solution (containing $0.08 \mathrm{~g} \mathrm{rhBMP}_{2}$ ) was dropped into the reactor systems. The resulting microspheres were washed 3 times with cool isopropanol, ethyl ether to remove the residual paraffin, washed with rhBMP $_{2}$ saturation water and then lyophilized, sized by passing through sieves of different apertures. The collected loaded microspheres were preserved in a desiccator. Unloaded microspheres were synthesized by the same procedure, with the exception of the concentrated $\mathrm{rhBP}_{2}$ solution added and $\mathrm{rhBMP}_{2}$ saturation water washing.

Morphology, size, and swelling analysis Freeze-dried microspheres were sprinkled onto a piece of electric-glue paper, gold-sprinkled in a vacuum and then examined by scanning electron microscopes (SEM,S-520, Hitachi, Japan). Size and size distribution were calculated by 500 microparticles during SEM and the roundness of the microspheres were determined by a particle size analyzer (BI-90, Brookhaven Co, California, USA). At the same time, freeze-dried microspheres ( $5 \mathrm{mg}$ ) were suspended in aqueous solution (4 $\mathrm{mL}$ ) for 5 min using an ultrasonic bath and then dropped onto a sheet glass. The morphology of swelling microspheres was observed by photomicroscope (XI 70, Olympus, Tokyo, Japan). Another solidified $\mathrm{rhBMP}_{2}$-MPs powder (weight $\mathrm{W}_{\mathrm{o}}$ of $5 \mathrm{mg}$ ) was dipped in aqueous solution for approximately $30 \mathrm{~min}$, then using filtered paper absorbed the water and weighed the weight of the swollen microspheres $\left(\mathrm{W}_{\mathrm{s}}\right)$. The swelling ratio (Rs) of the microspheres was calculated by the following formula:

$$
\operatorname{Rs}(\%)=\left(W_{\mathrm{s}}-W_{\mathrm{o}}\right) / W_{\mathrm{o}} \times 100 \%
$$

Determination of drug loading and drug encapsulation efficiencies Drug encapsulation efficiencies(DE) and drug loading (DL) are 2 main indexes of pharmaceutical forms. DE reflects the pharmaceutical form's ability to encapsulating drugs and high DE means little drug wasted during preparation, while DL reflects the effectual drug component in a pharmaceutical form and high DL means high therapeutic component available. They are all of great importance. The determination methods included an exact weighed amount of rhBMP $_{2}$-MPs (100 mg); unloaded microspheres $(100 \mathrm{mg})$ were treated with $50 \mathrm{~mL} \mathrm{NaOH}(10 \%, w / v)$ water solution at $80^{\circ} \mathrm{C}$ for $20 \mathrm{~min}$. Fully degraded dex-GMA/gelatin solution were adjusted to neutral solution with $3 \mathrm{~mol} \cdot \mathrm{L}^{-1} \mathrm{HCl}$ and centrifugated for $5 \mathrm{~min}$. The supernatants were mixed with total-ionic-strength adjusting buffer (TISAB II)and made into $50 \mathrm{~mL}$ of solution. Drug content in the solution were conducted by means of High Performance Liquid Chromatography (HPLC) (94-09SC, Orion Research Inc, Boston, MA, USA). The actual weight of $\mathrm{rhMP}_{2}$ found loaded should be 
equal to the remainder of the $\mathrm{rhBMP}_{2}$ contents between rhBMP $\mathrm{P}_{2}$-loaded and unloaded microspheres.

$\mathrm{DE}(\%)=\left(\right.$ Weight of $\mathrm{rhBMP}_{2}$ found loaded $) /($ Weight of rhBMP $_{2}$ input $) \times 100 \%$

DL $(\%)=\left(\right.$ Weight of $\mathrm{rhBMP}_{2}$ found loaded $) /($ Weight of rhBMP ${ }_{2}$-loaded microspheres $) \times 100 \%$

Biodegradation of $\mathbf{r h B M P} \mathbf{P}_{2}$-MPs Reports have been found to show that dextran-based biomaterials could be biodegraded in any liquid with presence a very tiny quantity of dextranase. Thirty-six exact weighed amounts of hbMP $_{2}-$ MPs $(100 \mathrm{mg})$ were dipped in $0.9 \%$ physiological saline (containing $0.05 \mu \mathrm{g} / \mathrm{mL}, 0.1 \mu \mathrm{g} / \mathrm{mL}$ and $0.2 \mu \mathrm{g} / \mathrm{mL}$ dextranase, respectively) and divided into 4 groups at certain time intervals of $10 \mathrm{~d}, 20 \mathrm{~d}, 30 \mathrm{~d}$, and $40 \mathrm{~d}$; three of each group were collected and freeze-dried. The morphology of the biodegraded microspheres was observed by SEM and weight loss was also studied.

Stability and biological activities of $\mathbf{r h B M P}_{2}$-MPs Dry rhBMP 2 -MPs were sealed and deposited in a $4{ }^{\circ} \mathrm{C}$ refrigerator or at room temperature for 6 months respectively. Their appearance, morphology, DE and DL were checked as routine procedure. The bioactivity of the microspheres were evaluated by the biological effects they had on the cultured cells in vitro, and at the same time, we investigated the biological effects of loaded microspheres compared to the equivalent concentrated $\mathrm{rhBMP}_{2}$ solution. Human periodontal ligament cells (PDLCs) were obtained from premolars extracted for orthodontic reasons from a 14-year-old patient, using cultured methods as previously described by Somerman et $a l^{[26]}$. The protocol was approved by the Ethical Committee in Research from the Fourth Military Medical University. The cell growth assay was performed by MTT (purchased from Sigma, Saint-Louis, MO, USA) methods ${ }^{[27]}$. Generally, PDLCs were placed in a 96-well culture plate (Nunc A/S, Roskilde, Denmark) at a density of 30,000 cells/well in $2 \mu \mathrm{L}$ of DMEM containing 10\% FBS and antibiotics. After $16 \mathrm{~h}$, the cells were washed with PBS and cultured in serumfree(CT)-FBS/DMEM supplemented with $100 \mu \mathrm{g} / \mathrm{mL} \mathrm{rhBMP}_{2}$ (group I) or $782 \mu \mathrm{g} / \mathrm{mL} \mathrm{rhBMP}_{2}$-MPs synthesized within $3 \mathrm{~d}$ (equal to $100 \mu \mathrm{g} / \mathrm{mL} \mathrm{rhBMP}_{2}$; group II), or $782 \mu \mathrm{g} / \mathrm{mL} \mathrm{rhBMP}_{2^{-}}$ MPs deposited in a $4{ }^{\circ} \mathrm{C}$ refrigerator for 6 months (group III), or at room temperature for 6 months (group IV), the control group (group IV) served as the control supplemented with nothing. After 1, 2, 3, 5, 7, 10, $12 \mathrm{~d}$, absorbance was read at $570 \mathrm{~nm}$ according to routine MTT methods. The cellular proliferation was calculated as the amount of MTT uptake.

Drug release study in vitro In vitro drug release profiles were obtained by a dynamic dialysis method simulating the temperature in vivo. Briefly, 3 groups of $\mathrm{rhBMP}_{2}$-MPs (50 $\mathrm{mg})$, according to different quantity of TEMED $(0.01 \mathrm{~mL}$, $0.02 \mathrm{~mL}$ and $0.03 \mathrm{~mL}$ ) when prepared, were poured into a dialysis tube (IL61105, Rockford, USA), then placed at $37.0 \pm 0.5^{\circ} \mathrm{C}$ into phosphate buffer solution (PBS) of $150 \mathrm{~mL}$ $(\mathrm{pH}=7.0)$, respectively, and continuously stirred with a magnetic stirrer at $200 \mathrm{r} / \mathrm{min}$. At specific time intervals of $5 \mathrm{~h}$, $20 \mathrm{~h}, 30 \mathrm{~h}, 60 \mathrm{~h}, 90 \mathrm{~h}, 120 \mathrm{~h}, 150 \mathrm{~h}, 190 \mathrm{~h}$, and $250 \mathrm{~h}, 10 \mathrm{~mL}$ of samples were removed from the release medium and the same volume and temperature of PBS was added back to the release medium. The samples were then assayed for drug content according to intraday standard curve. Results of triplicate test data were used to calculate accumulated drug release. Cumulative release profiles of different rhBMP $_{2}-\mathrm{MPs}$ were studied respectively.

CPC/rhBMP ${ }_{2}$-MPs scaffolds preparation The calcium phosphate ceremic (CPC) was purchased from Rui Bang Biomaterial Inc (Shanghai, China) and $\mathrm{CPC} / \mathrm{rhBMP}_{2}-\mathrm{MPs}$ was obtained by a physical concoction mechanism using CPC, $\mathrm{PBS}$, and $\mathrm{rhBMP}_{2}$-MPs with the inverse proportion being 1:3:0.01, and then solidified in a vacuum desiccator. Human PDLCs cultured in vitro were collected and seeded on the concreting compound, the cell growth in the scaffolds and $\mathrm{CPC} / \mathrm{rhBMP}_{2}-\mathrm{MPs}$ framework were observed by SEM.

Animal experiment After receiving approval from the Committee of Research Facilities for Laboratory Animal Science, Fourth Military Medical University, 12 female beagle dogs weighing 10 to $14 \mathrm{~kg}$ and aged 12 to 20 months were used in this study. Good oral health was established by scaling and mechanical tooth-brushing. All surgical procedures were performed under general anesthesia with sodium pentobarbital $(40 \mathrm{mg} / \mathrm{kg})$, and local infiltrated anesthesia with 2\% lidocaine with 1:80 000 noradrenaline. Experimental Class III furcation defects prepared in this study were based on the model described by Lindhe et $a l^{[28]}$. The second, third, and fourth premolars (P2, P3, and P4) in each dog were selected for experimentation (Figure 1A). Following sulcular incisions, mucoperiosteal flaps were raised, and Class III furcation defects were created surgically at P2, P3, and P4. The Class III defect height from the cemento-enamel junction to the reduced alveolar crest was $5.00 \pm 0.20 \mathrm{~mm}$. Denuded root surfaces were prepared to remove all periodontal ligament and cementum. The roots were denuded only in the area within the furcation and extending to the mesial line angle for the mesial root and to the distal line for the distal root. Reference notches were placed around the circumference of the mesial and distal roots at the bottom of the bone level. All teeth were divided into 4 sub areas: maxillary left and right, submaxilla left and right, and then divided into 2 groups stochastically (to avoid the interaction of defects in 

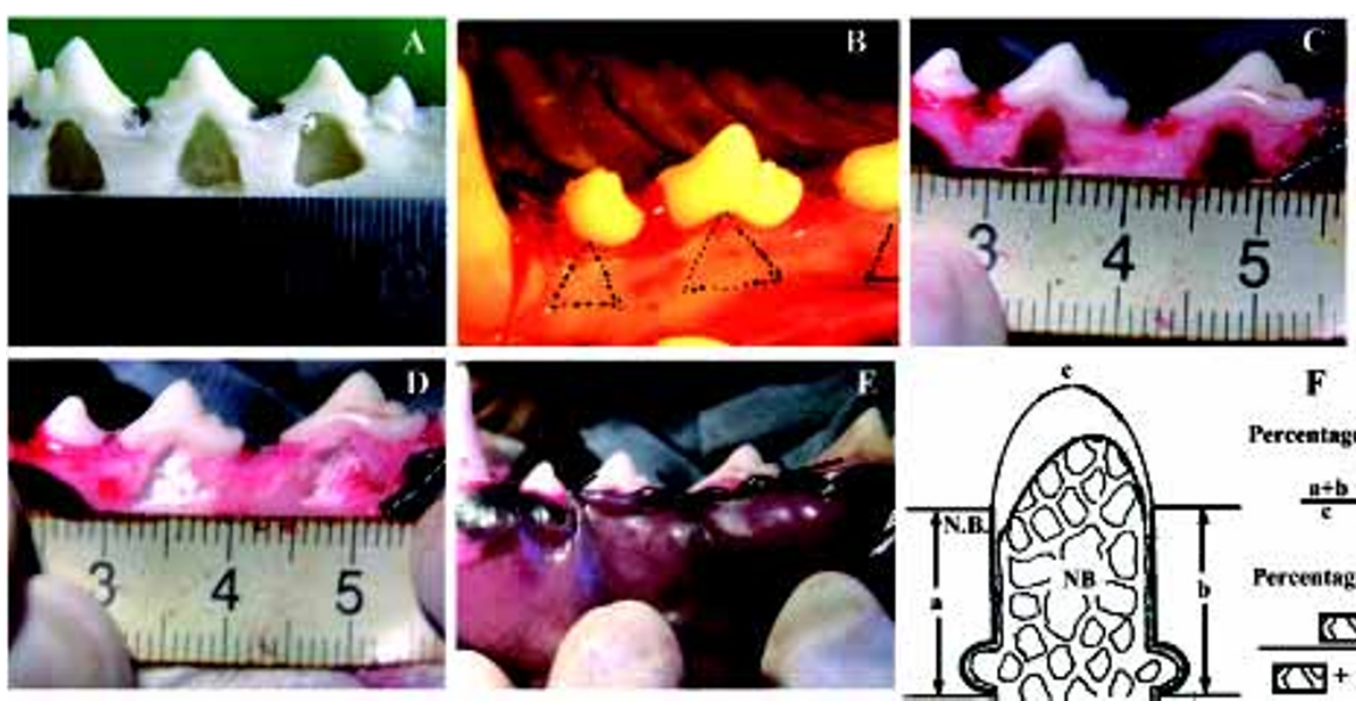

$\mathbf{F}$

Percentage of NC length

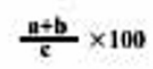

Pereentage of NB area

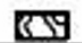

$\mathbb{B}$

Figure 1. Animal experiment (A) Lindhe's model of Class III furcation defects; (B) Presurgical view of the mandibular premolar area and Class III furcation defects circumscription demarcation; (C) After defect preparation; (D) After transplantation of CPC/rhBMP ${ }_{2}$-MPs scaffolds; (E) After repositioning of gingival flaps and suturing; (F) Schematic drawing of percentage of new cementum length and percentage of new bone.

one subarea): the experimental group and the control group. The experimental group was transplanted with $\mathrm{CPC} / \mathrm{rhBMP}_{2}-$ MPs scaffolds while the control group was transplanted with CPC concreting compound soaked with the commensurate quantity of concentrated rhBMP ${ }_{2}$ compared with $\mathrm{rhBMP}_{2}-$ MPs. In another words, the actual rhBMP ${ }_{2}$ quantity transplanted into each Class III furcation defects was exactly same (Figure 1B, 1C, 1D, 1E). One or 2 months after transplantation, anesthetized animals were perfused with $1 \%$ glutaraldehyde in a sodium cacodylate buffer containing $0.05 \%$ calcium chloride ( $\mathrm{pH}$ 7.3). The periodontal tissue regeneration was evaluated by unaided eye and X-ray. After that, the mandibles and maxillas were dissected and immersed in the same fixative. After decalcification with hydrochloride for 3 to $5 \mathrm{~d}$, the mandibles and maxillas were dehydrated in paraffin. Serial section $(5 \mu \mathrm{m})$ were cut in the mesial-distal plane throughout the buccal-lingal extension of the tooth. The sections were stained with hematoxylin and eosin (HE) or the Azan method, and observed using a light microscope. The center-most section and the immediate section on either side were subjected to morphometric analysis. The percentage of new cementum (NC) length and percentage of new bone (NB) area were measured on digitized photomicrographs captured in a computer. The lengths of NC formed along the denuded root surface on each specimen were added, and the percentage of the lengths to the total root surface length from one notch to the next notch was calculated. The area of NB on each specimen was calculated as a percentage of the area surrounded with reference notches at mesial and distal root surfaces space is present in normal periodontal tissue (Figure 1F). All data were statistically analyzed using the MannWhitney U test.

\section{Results}

Morphology and particle size The SEM photomicrographs of dried rhBMP $\mathrm{P}_{2}$-MPs showed a smooth and uniform surface (Figure 2A). The roundness of microspheres was $1.020 \pm 0.005$. The average diameter was $(30.33 \pm 4.32) \mu \mathrm{m}$ with $75.4 \%$ ranging from $20 \mu \mathrm{m}$ to $40 \mu \mathrm{m}$, The swelling ratio for solidified and dried microspheres was $4.18 \pm 0.06$, and the size of the soggy microspheres size was approximately $5-10$ times larger (Figure 2B). The morphology and particle size analysis showed no difference between loaded and unloaded freeze-dried or swelling microspheres, but when the swelling microspheres were sprinkled onto a piece of glass, half freezedried and then observed through a photomicroscope (XI 70, Olympus), the loaded microspheres were found to be a little fuscous. The unloaded microspheres were briefly translucent (Figure 2C, 2D), which was perhaps caused by the increase of the microspheres' density when drugs were encapsulated into the microspheres. Thus, we could presume that drug encapsulation was the primary drug association mechanism of dex-GMA-co-gelatin microspheres.

DL and DE The calculated results of DL and DE were $7.82 \%$ and $82.25 \%$, respectively. In the present study, we achieved optimal preparation parameters using the orthogonal design, which was rhBMP $2\left(0.5 \mathrm{mmol} \cdot \mathrm{L}^{-1}\right)$, dex-GMA/gelatin solution $(20 \%, m / v)$, emulsifying agent $(1 \%, m / v)$, and $1: 5$ 

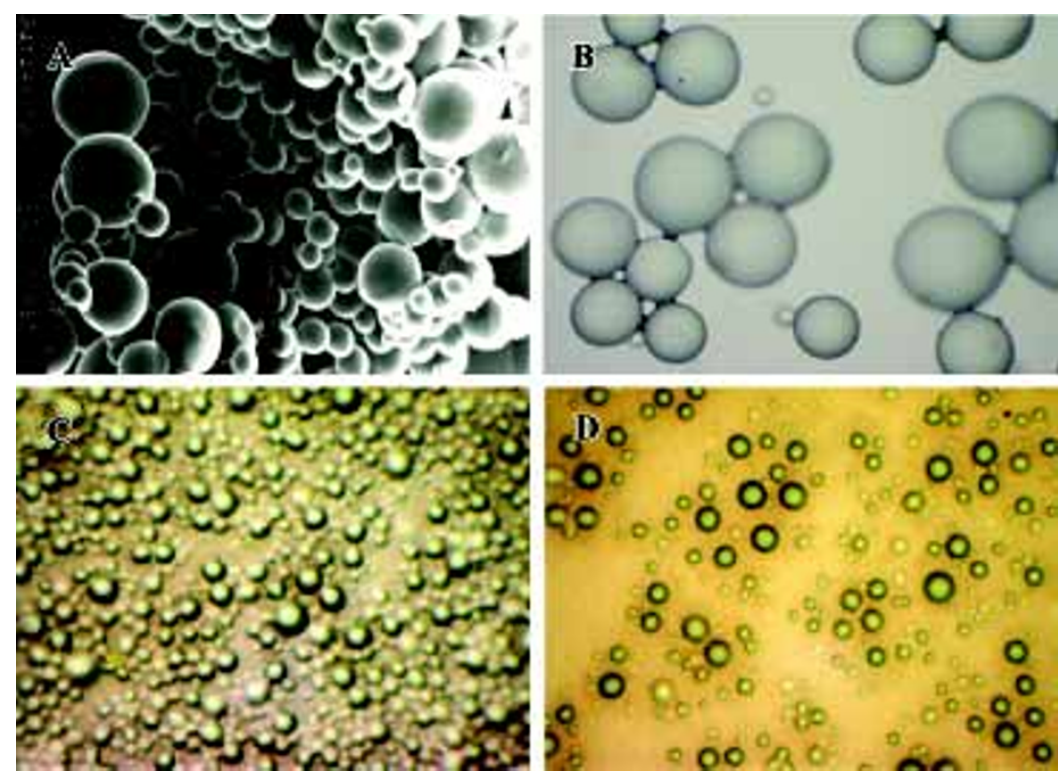

Figure 2. Micrographs of rhBMP ${ }_{2}$-MPs. (A) SEM micrographs of dried rhBMP$_{2}$-MPs $(\times 400)$; (B) Optical micrographs of soggy $\mathrm{rhBMP}_{2}-\mathrm{MPs}(\times 100) ;(\mathrm{C})$ Loaded microspheres $(\times 100)$; (D) Unloaded microspheres $(\times 100)$.

$(v / v)$ of water phase to oil phase. During the experiment we discovered that the concentration of $\mathrm{rhBMP}_{2}$ affected the quality of the microspheres. When the content of $\mathrm{rhBMP}_{2}$ exceeded $1 \mathrm{mmol} / \mathrm{L}$, the microspheres' morphology was not uniform, and was prone to sticking. When the concentration was lower than $0.1 \mathrm{mmol} / \mathrm{L}$, the drug content was also too low and thus, unfit for practical application. In order to reduce the loss of $\mathrm{rhBM}_{2}$ during the process of preparation, and improve the encapsulation efficiencies, presolidification was introduced and microspheres were washed with concentrated $\mathrm{rhBMP}_{2}$ solution. Glutaraldehyde $(25 \%, v / v)$ was used to solidify; the solidification time was over $24 \mathrm{~h}$. The encapsulation efficiencies of $\mathrm{rhBMP}_{2}$-MPs reached $86.73 \%$, which was much higher than other biomaterials that have been reported ${ }^{[29]}$.

Biodegradation of rhBMP $\mathbf{P}_{2}-\mathrm{MPs} \quad \mathrm{rhBMP}_{2}-\mathrm{MPs}_{\mathrm{s}}$ could completely degrade within $30-40 \mathrm{~d}$ by dextranase action (Figure 3). The weight at specific time intervals was shown in Figure 4, and the microspheres eventually dissolved. However, Figure 4 also shows that the degraded speed in-

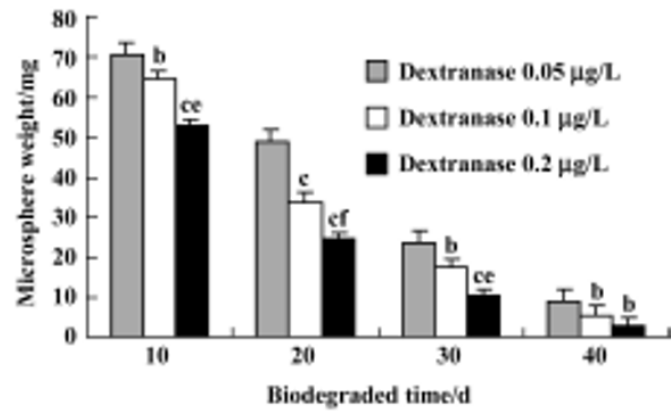

Figure 4. Weight of $\mathrm{rhBMP}_{2}$-MPs at certain time intervals when degraded under conditions with different quantities of dextranase which showed significant difference. $n=4$. Mean \pm SEM. ${ }^{\mathrm{b}} P<0.05,{ }^{\mathrm{c}} P<0.05 v s$ dextranase $0.05 \mu \mathrm{g} / \mathrm{L}$. ${ }^{\mathrm{e}} P<0.05,{ }^{\mathrm{f}} P<0.05 v s$ dextranase $0.1 \mu \mathrm{g} / \mathrm{L}$.

terrelated closely to the consistence of dextranase. This might have important clinical meanings. In periodontal diseases such as periodontitis, especially rapidly progressive periodontitis, when the prolific nosogenetic bacteria and organisms in local environment (which cause excessive dex-
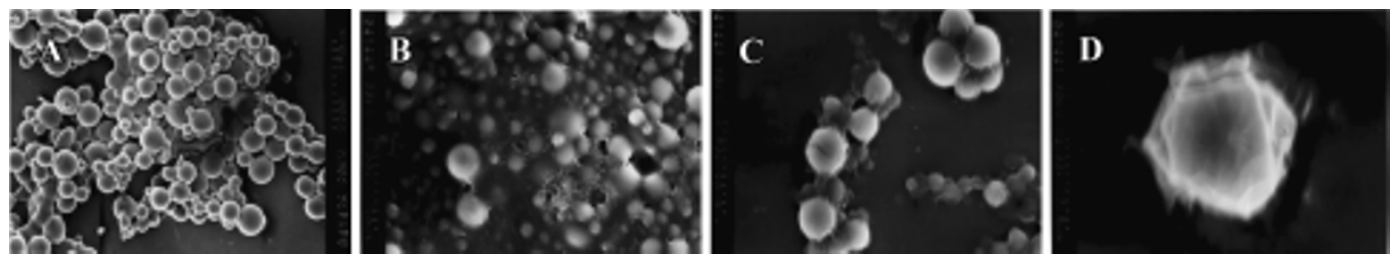

Figure 3. SEM of rhBMP ${ }_{2}-\mathrm{MPs}$ biodegradation in certain time intervals. (A) After $10 \mathrm{~d}$, rhBMP $\mathrm{MPs}_{2} \mathrm{MPegin}$ to be felted and dissolution can

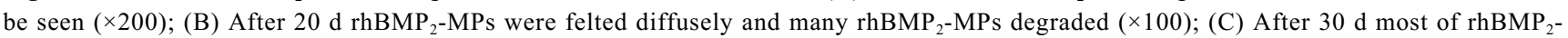
MPs degraded ( $\times 1500)$; (D) After $40 \mathrm{~d}$ most of rhBMP $_{2}-$ MPs disappeared and the surface of residuary rhBMP ${ }_{2}-\mathrm{MPs}_{\mathrm{s}}$ became scraggly $(\times 4000)$. 
tranase biosynthesis and the biodegradation of $\mathrm{rhBMP}_{2}$-MPs more rapidly), rapid releasing $\mathrm{rhMP}_{2}$ from microspheres is beneficial for tissue repair and at the same time, can prevent tissue loss. It could be hypothesized that when $\mathrm{rhBP}_{2}-$ MPs are topically applied, their presence in the periodontal environment, even at low concentrations, can prevent demineralization as well as promote remineralization of incipient lesions through $\mathrm{rhBMP}_{2}$ release which are quickened under more dextranase conditions.

Stability of rhBMP $\mathbf{2}_{2}$-MPs The rhBMP ${ }_{2}$-MPs were stable when sealed and stored below $4{ }^{\circ} \mathrm{C}$ for 6 months without obvious physical and chemical characteristics change. However, when stored at room temperature, $\mathrm{rhBMP}_{2}$-MPs biomorphic characteristic could not keep unchangeable and with a configuration of conglutination and abnormity (Figure 5). The proliferation curves of PDLCs in different groups are shown in Figure 6. Cytology studies showed that there was no significant differences between groups II and III $(P>$ $0.05)$, indicating no significant bioactivity loss of $\mathrm{rhBM}_{2}-$ MPs when stored below $4{ }^{\circ} \mathrm{C}$ for 6 months. On the other hand, after 6 months of being stored at room temperature, rhBMP $\mathrm{P}_{2}$-MPs would no longer have any biological activity $(P<0.01)$. In addition, the $\mathrm{rhBMP}_{2}$-MPs could enhance the proliferation of PDLCs for more than $12 \mathrm{~d}$ continuously, while the pute $\mathrm{rBMP}_{2}$ bioactivity could function only in $3 \mathrm{~d}$, which also showed the sustained delivery property of $\mathrm{rhBMP}_{2}$-MPs (Figure 6).

In vitro release studies The release profiles of $\mathrm{rhBP}_{2}$ from microspheres as a function of time showed that $\mathrm{rhBP}_{2}-$
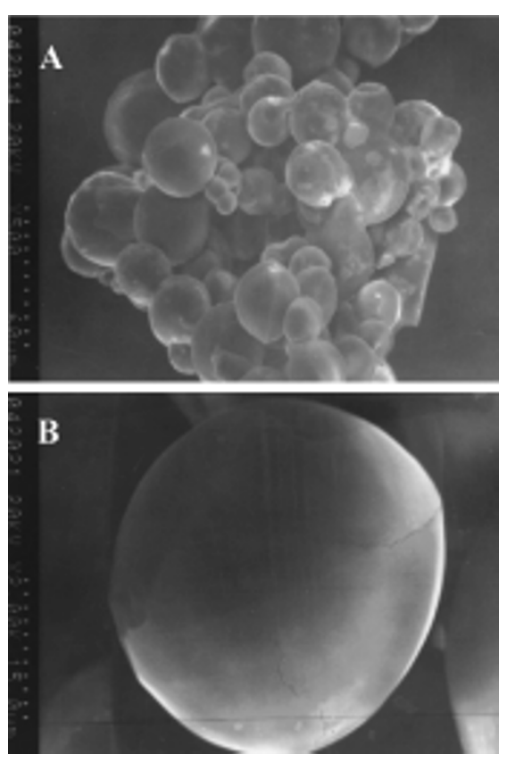

Figure 5. SEM of rhBMP ${ }_{2}$ MPs stored at room temperature after 6 months. (A) $\times 500$; (B) $\times 2000$.

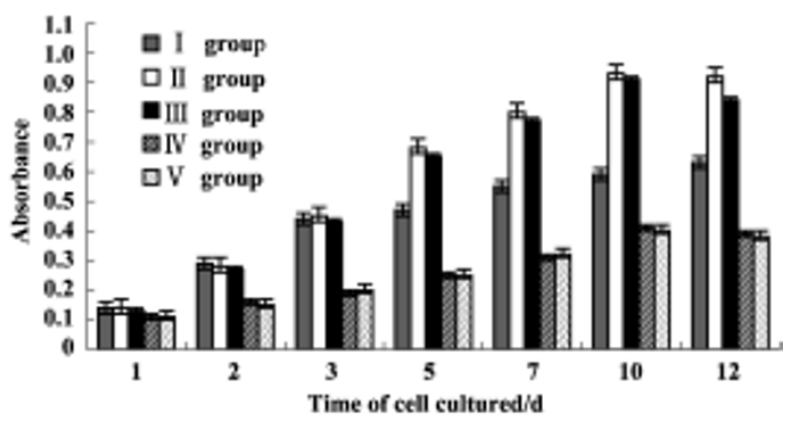

Figure 6. Enhancement effect on the proliferation responses of PDLCs by different cultured medium.

releasing kinetics in vitro fitted to first-order and Higuchi equations. From Figure 7 we could see that the drug release from rhBMP $\mathrm{P}_{2}$-MPs mainly consisted of 2 components with an initial rapid release followed by a slower exponential stage. The release profile in vitro was in accord with 2-phase kinetics law and more than $80 \%$ of the drugs were released during the first $10 \mathrm{~d}$. Furthermore, changing the quantity of TEMED could influence drug release; rhBMP 2 release from rhBMP ${ }_{2}^{-}$ MPs was slower when the quantity of TEMED was increased during preparation, which could be caused by the DS of microspheres increase followed with TEMED increased. During the initial stages, the microspheres were absorbed and the sphere enlarged rapidly; the drugs were rapidly released from the microspheres through the exoteric microaperture; When swelling was counterpoise, the drug release slowed down and was determined by drug pervasion and microsphere biodegradation. Thus, we can speculate that rhBMP ${ }_{2}$ release from rhBMP $\mathrm{PMP}_{2}$ might be controlled by some preparation technique change.

Cells growth on $\mathbf{C P C} / \mathbf{r h B M P}_{2}$-MPs scaffolds A scanning electron microscope showed that the porous structure

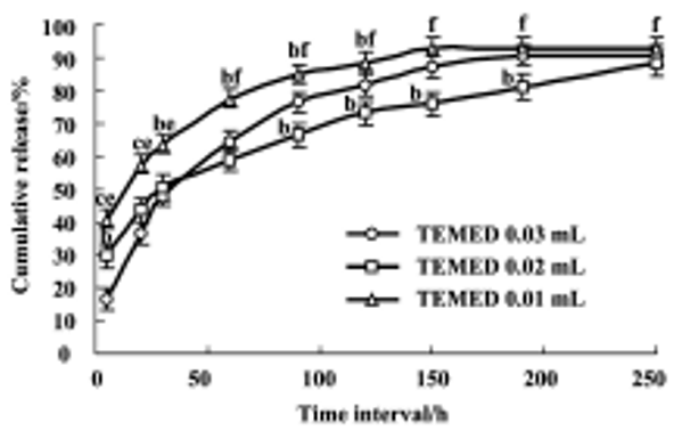

Figure 7. Cumulative release profiles of different $\mathrm{rhBMP}_{2}$-MPs prepared with different quantities of TEMED. $n=4$. Mean \pm SEM. ${ }^{\mathrm{b}} P<0.05,{ }^{\mathrm{c}} P<0.05$ vs TEMED $0.03 \mathrm{~mL} .{ }^{\mathrm{e}} P<0.05,{ }^{\mathrm{f}} P<0.05$ vs TEMED $0.02 \mathrm{~mL}$. 
of $\mathrm{CPC} / \mathrm{rhBMP} \mathrm{P}_{2}-\mathrm{MPs}$ compound and $\mathrm{rhBMP}_{2}-\mathrm{MPs}$ could be adhered in the porous structure (Figure $8 \mathrm{~A}$ ). After $3 \mathrm{~d}$, human PDLCs could grow on $\mathrm{CPC} / \mathrm{rhBMP}_{2}$-MPs compound both in the porous structure (Figure $8 \mathrm{~B}$ ) and on the material's surface (Figure 8C).

Animal experiment When observed with unaided eye in the experimental group, the defect was well regenerated after 1 month (Figure 9A) and was almost completely regenerated after 2 months (Figure 9B). The control group gained less tissue regeneration than the experimental group even after 2 months (Figure 9C). The X-ray observation results were shown in Figure 10. In the experimental group, a significant amount of new bone and an adequate width of periodontal ligament were observed (Figure 11A). The denuded root surface was almost completely covered with NC, and regenerated periodontal ligament separated the NB from the cementum. On the denuded root surfaces of the furcation area, newly formed cementum covered the surface, and the Sharpey's fibers inserted into the cementum were frequently observed (Figure 11B). In the control group, no cementum regeneration was observed (Figure 11C) and epithelial cells invaded into the top of the furcation in the area (Figure11D). Less bone regeneration was observed in this group compared to the experimental group. The percentages of $\mathrm{NC}$ length in the experimental group after 1 and 2 months were $93.9 \% \pm 14.2 \%$ and $96.7 \% \pm 5.29 \%$, respectively, compared to $70.4 \% \pm 12.1 \%$ and $72.8 \% \pm 9.2 \%$ in the control group. The results showed significant difference $(P<0.01)$. Accordingly,
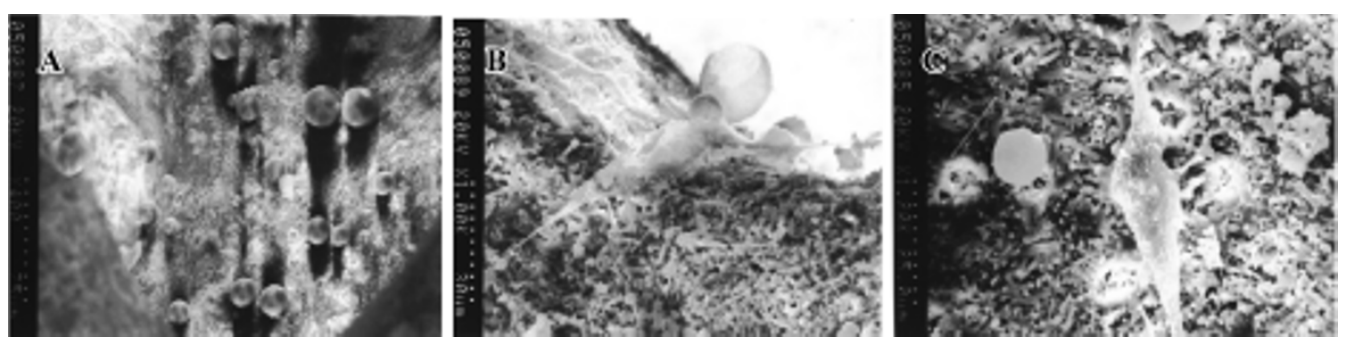

Figure 8. SEM of $\mathrm{CPC} / \mathrm{rhBMP} \mathrm{P}_{2}$-MPs scaffolds and cell growth. (A) CPC/rhBMP - -MPs scaffolds $(\times 400)$; $(\mathrm{B}, \mathrm{C})$ Cell growth on $\mathrm{CPC} / \mathrm{rhBMP}{ }_{2}-\mathrm{MPs}$ scaffolds $(\times 1000)$.
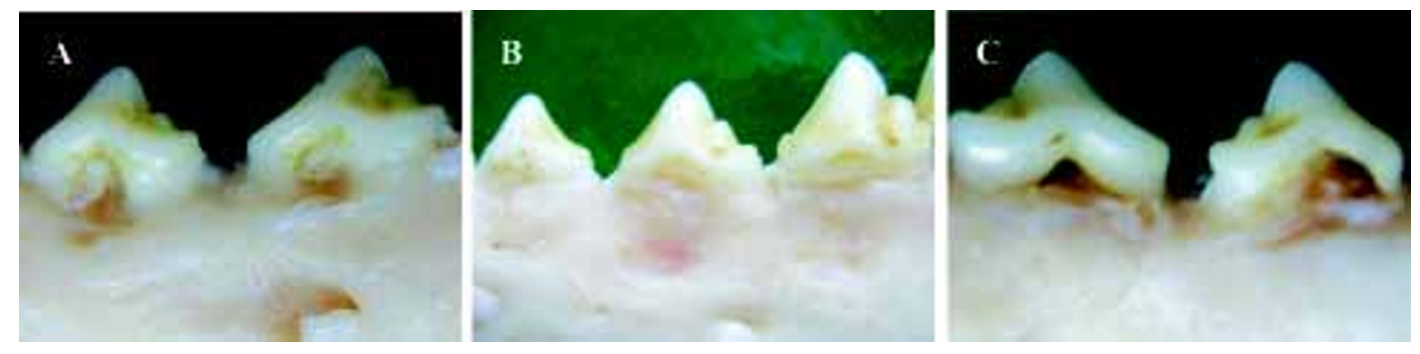

Figure 9. Tissue regeneration observed with unaided eye. (A) After 1 month experimental group; (B) After 2 months experimental group; (C) After 2 months control group.
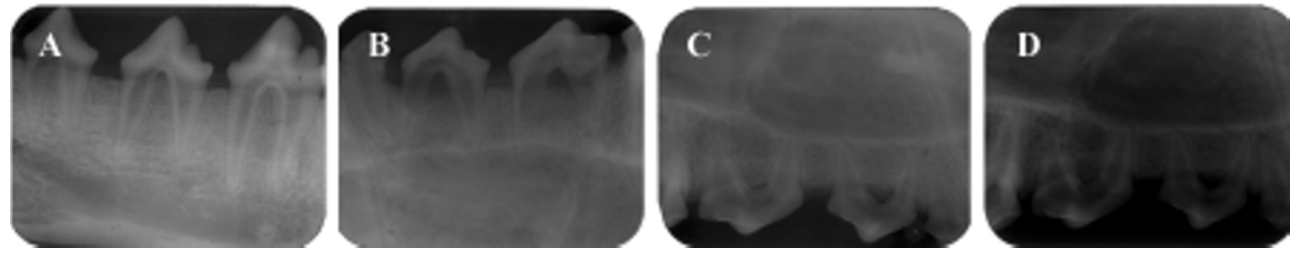

Figure 10. Tissue regeneration observed with X-ray after 2 months. (A) Tooth in mandible experimental group, well-regeneration in the Class III furcation defect area could be seen and the radiograph was on the verge of normal dental film; (B) Tooth in mandible control group, shadow in the furcation area was still obvious; (C) Tooth in maxilla experimental group, bone image in the furcation defect area showed well bone regeneration; (D) Tooth in maxilla control group, compared to experimental group, little new bone could be observed. 

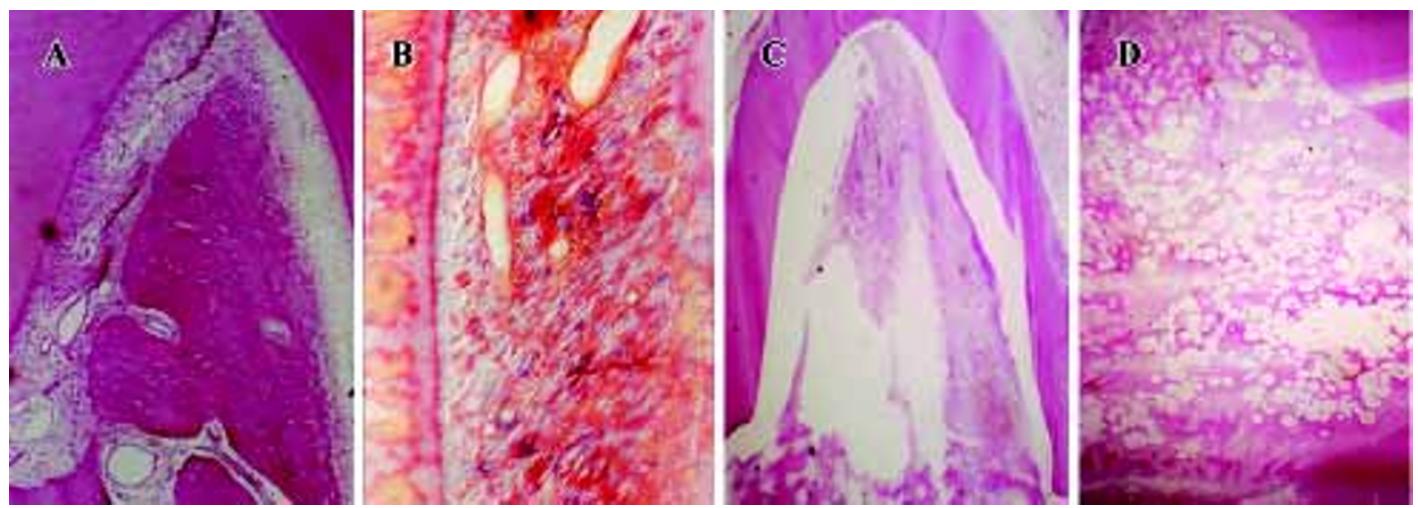

Figure 11. Histological analysis of periodontal tissue regeneration after 2 months. (A) HE $\times 13$ experimental group. After 2 months, there was a significant amount of NB and NC; (B) Azan method $\times 100$ experimental group. An adequate width of periodontal ligament can be observed; (C) HE $\times 13$ control group. Less NB and NC can be observed; (D) HE $\times 100$ control group. Epithelial cells invaded the top of the furcation.

the percentages of NB were $62.6 \% \pm 13.5 \%$ and $68.7 \% \pm 9.73 \%$ in the experimental group and $54.7 \% \pm 10.73 \%$ and $57.3 \% \pm$ $11.2 \%$ in the control group also showed significant difference $(P<0.01)$.

\section{Discussion}

Biodegradable hydrogel microspheres are attractive devices for drug release because they combine good tissue biocompatibility with the possibility of manipulating the permeability for solutes. In particular, their use in pharmaceutics shows promise since recent advancements in biotechnology have led to a great variety of pharmacologically active peptides and proteins that are not adequately released from systems that are not biodegradable. Degradation of the hydrogel microspheres not only allows a tailored release of entrapped molecules, but also circumvents the removal of the empty device from the body ${ }^{[30-32]}$. Although the use of biodegradable hydrogel microspheres related to prolonged and/or controlled drug delivery has been widely investigated, the need for the development of hydrogels using simpler and more feasible methods still exists. Among the starting materials, polysaccharides and polyaminoacids represent good candidates to prepare biodegradable hydrogels by photocrosslinking reactions. Besides their biocompatibility and biodegradability, these polymers can also have functional groups incorporated into their structures. These functional groups include acrylic or methacrylic ones, which can easily lead to the formation of inter- and intra-chain bonds by UV irradiation. In this context, the synthesis and characterization of dextran-co-gelatin hydrogel microspheres show good biocompatibility and biodegradability. Dextran is a natural polysaccharide that is widely used in the pharma- ceutical field $^{[33-37]}$. It is water soluble, inert in biological systems and does not affect cell viability. The characteristic $\alpha$ 1,6-glucosidic linkage is hydrolyzed by dextranases, enzymes produced by various molds and certain bacteria as well as by mammalian cells. It has also been found that dextranases are produced by anaerobic Gram-negative intestinal bacteria $^{[38]}$. The use of hydrogels based on dextran represents a strategy to release drug molecules in the colon after hydrolysis of the polysaccharide microspheres ${ }^{[39]}$. After sucking and swelling in vivo, $\mathrm{rhBM}_{2}$-MPs can keep rhBMP $\mathrm{rm}_{2}$ concentrations over prolonged periods of time, which might be explained by the sustained-release of rhBMP ${ }_{2}$ from rhBMP $_{2}-$ MPs and dextran-based microspheres' bioadhesive properties to mouth parenchyma. Experiments conducted using rhBMP ${ }_{2}-\mathrm{MPs}$ and $\mathrm{rhBMP}_{2}$ solution as control revealed that rhBMP ${ }_{2}-\mathrm{MPs}_{\mathrm{s}}$ maintained $\mathrm{rhBM}_{2}$ elevation above baseline for about $10 \mathrm{~d}$, but rhBMP ${ }_{2}$ maintained for less than $3 \mathrm{~d}$. This indicated the possibility that $\mathrm{rhBMP}_{2}$-MPs could meet clinical intermittent administration by prolonging $\mathrm{rhBMP}_{2}$ retention time significantly.

Many biomaterials such as Chitosan, polylacticacid (PLA), polyglycolicacid (PGA), PGA-co-PLA polymers (PLGA), poly (ethylene glycol) (PEG), gelatin, and polybutylcyanoacrylate (PBCA) were all reported to prepare growth factorsustained release systems recently, but a lot of questions remain unanswered. The outstanding obstacle in the clinical application of growth factor carriers to promote tissue regeneration and control release of growth factors is still unrealized, which results in the growth factors not being able to maintain enough time or concentration during the tissue regenerated period. To meet the need of periodontal regeneration, new biomaterials used to prepare controlled release system of growth factors have become increasingly 
important. From this study, we prepared a new carrier for the sustained release of $\mathrm{rBMP}_{2}$, which can be used to synthesize guided tissue regeneration biomembranes and build functional scaffolds in tissue engineering. In summary, for the first step in developing a new type of $\mathrm{rhBMP}_{2}$ agent, we chose dextran-based micropsheres as sustained release carriers for topical $\mathrm{rhBMP}_{2}$ applications. We proved the ability of $\mathrm{rhMP}_{2}$-MPs in prolonging $\mathrm{rhBM}_{2}$ release and their potential in prohibiting demineralization and enhancing the rhBMP $_{2}$ retention both in vitro and in vivo. This work offered a new method in contributing growth factors, not only BMPs, but also other growth factors for clinical use, which can be popularized with further evaluation both in animal experiment and in clinical cases. However, some limitations of using the microsphere-carrier combination, including the potential difficulty in manufacturing the carrier, and the expensive price considering the costly price of growth factors themselves. Moreover, the manufacture procedure and the application of this pharmaceutical form still require further study both experimentally and clincally.

\section{References}

1 Yu TT, Shoichet MS. Guided cell adhesion and outgrowth in peptide-modified channels for neural tissue engineering. Biomaterials 2005; 26: 1507-14.

2 Cheng MH, Brey EM, Allori A, Satterfield WC, Chang DW, Patrick $\mathrm{CW} \mathrm{Jr}$, et al. Ovine model for engineering bone segments. Tissue Eng 2005; 11: 214-25.

3 Choo AB, Padmanabhan J, Chin AC, Oh SK. Expansion of pluripotent human embryonic stem cells on human feeders. Biotechnol Bioeng 2004; 88: 321-31.

4 Hsu SH, Tsai CL, Tang CM. Evaluation of cellular affinity and compatibility to biodegradable polyesters and type-II collagenmodified scaffolds using immortalized rat chondrocytes. Artif Organs 2002; 26: 647-58.

5 Kim SS, Vacanti JP. The current status of tissue engineering as potential therapy. Semin Pediatr Surg 1999; 8: 119-23.

6 Sorensen RG, Wikesjo UM, Kinoshita A, Wozney JM. Periodontal repair in dogs: evaluation of a bioresorbable calcium phosphate cement (Ceredex) as a carrier for rhBMP-2. J Clin Periodontol 2004; 31: 796-804.

7 Wikesjo UM, Sorensen RG, Kinoshita A, Jian Li X, Wozney JM. Periodontal repair in dogs: effect of recombinant human bone morphogenetic protein-12 (rhBMP-12) on regeneration of alveolar bone and periodontal attachment. J Clin Periodontol 2004; 31: 662-70.

8 Hanisch O, Sorensen RG, Kinoshita A, Spiekermann H, Wozney JM, Wikesjo UM. Effect of recombinant human bone morphogenetic protein-2 in dehiscence defects with non-submerged immediate implants: an experimental study in Cynomolgus monkeys. J Periodontol 2003; 74: 648-57.

9 Camargo PM, Lekovic V, Weinlaender M, Vasilic N, Madzarevic M, Kenney EB. A reentry study on the use of bovine porous bone mineral, GTR, and platelet-rich plasma in the regenerative treatment of intrabony defects in humans. Int J Periodontics Restorative Dent 2005; 25: 49-59.

10 Wikesjo UM, Qahash M, Thomson RC, Cook AD, Rohrer MD, Wozney JM, et al. rhBMP-2 significantly enhances guided bone regeneration. Clin Oral Implants Res 2004; 15: 194-204.

11 Wikesjo UM, Xiropaidis AV, Thomson RC, Cook AD, Selvig KA, Hardwick WR. Periodontal repair in dogs: space-providing ePTFE devices increase rhBMP-2/ACS-induced bone formation. J Clin Periodontol 2003; 30: 715-25.

12 Wikesjo UM, Xiropaidis AV, Thomson RC, Cook AD, Selvig KA, Hardwick WR. Periodontal repair in dogs: rhBMP-2 significantly enhances bone formation under provisions for guided tissue regeneration. J Clin Periodontol 2003; 30: 705-14.

13 Ripamonti U, Reddi AH. Tissue engineering, morphogenesis, and regeneration of the periodontal tissues by bone morphogenetic proteins. Crit Rev Oral Biol Med 1997; 8: 154-63.

14 Nevins M, Camelo M, Nevins ML, Schenk RK, Lynch SE. Periodontal regeneration in humans using recombinant human platelet-derived growth factor-BB (rhPDGF-BB) and allogenic bone. J Periodontol 2003; 74: 1282-92.

15 Park YJ, Ku Y, Chung CP, Lee SJ. Control release of plateletderived growth factor from porous poly ( $L$-lactide) membranes for guided tissue regeneration. J Control Release 1998 12; 51: 201-11.

16 Wikesjo UM, Razi SS, Sigurdsson TJ, Tatakis DN, Lee MB, Ongpipattanakul B, et al. Periodontal repair in dogs: effect of recombinant human transforming growth factor-beta1 on guided tissue regeneration. J Clin Periodontol 1998; 25: 475-81.

17 Rimondini L, Nicoli-Aldini N, Fini M, Guzzardella G, Tschon M, Giardino R. In vivo experimental study on bone regeneration in critical bone defects using an injectable biodegradable PLA/PGA copolymer. Oral Surg Oral Med Oral Pathol Oral Radiol Endod 2005; 99: 148-54.

18 Hench LL, Xynos ID, Polak JM. Bioactive glasses for in situ tissue regeneration. J Biomater Sci Polym Ed 2004; 15: 543-62.

19 Schmokel HG, Weber FE, Seiler G, von Rechenberg B, Schense JC, Schawalder P, et al. Treatment of nonunions with nonglycosylated recombinant human bone morphogenetic protein-2 delivered from a fibrin matrix. Vet Surg 2004; 33: 112-8.

20 Holland TA, Tessmar JK, Tabata Y, Mikos AG. Transforming growth factor-beta 1 release from oligo (poly(ethylene glycol) fumarate) hydrogels in conditions that model the cartilage wound healing environment. J Control Release 2004; 94: 101-14.

21 Vandelli MA, Rivasi F, Guerra P, Forni F, Arletti R. Gelatin microspheres crosslinked with $D, L$-glyceraldehyde as a potential drug delivery system: preparation, characterisation, in vitro and in vivo studies. Int $\mathrm{J}$ Pharm 2001; 215: 175-84.

22 Brime B, Ballesteros MP, Frutos P. Preparation and in vitro characterization of gelatin microspheres containing levodopa for nasal administration. J Microencapsul 2000; 17: 777-84.

23 Morimoto K, Katsumata H, Yabuta T, Iwanaga K, Kakemi M, Tabata $\mathrm{Y}$, et al. Evaluation of gelatin microspheres for nasal and intramuscular administrations of salmon calcitonin. Eur $\mathrm{J}$ Pharmacol Sci 2001; 13: 179-85.

24 Nakase H, Okazaki K, Tabata Y, Uose S, Ohana M, Uchida K, et al. Development of an oral drug delivery system targeting immune-regulating cells in experimental inflammatory bowel disease: 
a new therapeutic strategy. J Pharmacol Exp Ther 2000; 292: 15-21.

25 Chen FM, Wu ZF, Jin Y, Wang QT, Wu H, Wang GF, et al. Development of a hydrogel microsphere delivery system for rhBMP $_{2}$. J Pract Stomatol 2005; 21: 174-7. Chinese.

26 Someman MJ, Foster RA, Vorsteg GM, Progebin K, Wynn RL. Effects of minocycline on fibroblast attachment and spreading. J Periodontal Res 1988; 23: 154-9.

27 Coletta RD, Almeida OP, Graner E, Page RC, Bozzo L. Differential proliferation of fibroblast cultured from hereditary gingival fibromatosis and normal gingival. J Periodontal Res 1998; 33 : $469-75$.

28 Lindhe J, Pontoriero R, Berglundh T, Araujo M. The effect of flap management and bioresorbable occlusive devices in GTR treatment of degree III furcation defects. An experimental study in dogs. J Clin Periodontol 1995; 22: 276-83.

29 Ko JA, Park HJ, Hwang SJ, Park JB, Lee JS. Preparation and characterization of chitosan microparticles intended for controlled drug delivery. Int J Pharm 2002; 249: 165-74.

30 Stenekes RJ, Franssen O, van Bommel EM, Crommelin DJ, Hennink WE. The preparation of dextran microspheres in an all-aqueous system: effect of the formulation parameters on particle characteristics. Pharm Res 1998; 15: 557-61.

31 Kamath KR, Park K. Biodegradable hydrogels in drug delivery. Adv Drug Delivery Rev 1993; 11: 59-84.
32 Kuijpers AJ, van Wachem PB, van Luyn MJ, Brouwer LA, Engbers $\mathrm{GH}$, Krijgsveld $\mathrm{J}$, et al. In vitro and in vivo evaluation of gelatinchondroitin sulphate hydrogels for controlled release of antibacterial proteins. Biomaterials 2000; 21: 1763-72.

33 Chourasia MK, Jain SK. Polysaccharides for colon targeted drug delivery. Drug Deliv 2004; 11: 129-48.

34 Harada M, Murata JI, Sakamura Y, Sakakibara H, Okuno S, Suzuki T. Carrier and dose effects on the pharmacokinetics of T-0128, a camptothecin analogue-carboxymethyl dextran conjugate, in non-tumor- and tumor-bearing rats. J Control Release 2001; 71: $71-86$.

35 Kojima T, Hashida M, Muranishi S, Sezaki HJ. Mitomyc in C dextran conjugate: a novel high molecular weight pro-drug of mitomycin C. J Pharm Pharmacol 1980; 32: 30-4.

36 Williams AS, Taylor G. Synthesis, characterization and release of cromoglycate from dextran conjugates. Int J Pharm 1992; 83: 233-9.

37 Kim IS, Jeong YI, Kim DH, Lee YH, Kim SH. Albumin release from biodegradable hydrogels composed of dextran and poly (ethylene glycol) macromer. Arch Pharm Res 2001; 24: 69-73.

38 Sery TW, Herhe EJ. Degradation of dextrans by enzymes of intestinal bacteria. J Bacteriol 1956; 71: 373-80.

39 Brondsted H, Andersen C, Hovgaard L. Crosslinked dextran-a new capsule material for colon targeting of drugs. J Control Release 1998; 53: 7-13. 